\title{
Validation of the Serbian version of inflammatory Rasch-built overall disability scale in patients with chronic inflammatory demyelinating polyradiculoneuropathy
}

Citation for published version (APA):

Peric, S., Bozovic, I., Pruppers, M. H. J., Bjelica, B., Stevic, Z., Faber, C. G., Merkies, I. S. J., \& Basta, I. (2019). Validation of the Serbian version of inflammatory Rasch-built overall disability scale in patients with chronic inflammatory demyelinating polyradiculoneuropathy. Journal of the Peripheral Nervous System, 24(3), 260-267. https://doi.org/10.1111/jns.12343

Document status and date:

Published: 01/09/2019

DOI:

$10.1111 /$ jns. 12343

Document Version:

Publisher's PDF, also known as Version of record

\section{Document license:}

Taverne

\section{Please check the document version of this publication:}

- A submitted manuscript is the version of the article upon submission and before peer-review. There can be important differences between the submitted version and the official published version of record. People interested in the research are advised to contact the author for the final version of the publication, or visit the DOI to the publisher's website.

- The final author version and the galley proof are versions of the publication after peer review.

- The final published version features the final layout of the paper including the volume, issue and page numbers.

Link to publication

\footnotetext{
General rights rights.

- You may freely distribute the URL identifying the publication in the public portal. please follow below link for the End User Agreement:

www.umlib.nl/taverne-license

Take down policy

If you believe that this document breaches copyright please contact us at:

repository@maastrichtuniversity.nl

providing details and we will investigate your claim.
}

Copyright and moral rights for the publications made accessible in the public portal are retained by the authors and/or other copyright owners and it is a condition of accessing publications that users recognise and abide by the legal requirements associated with these

- Users may download and print one copy of any publication from the public portal for the purpose of private study or research.

- You may not further distribute the material or use it for any profit-making activity or commercial gain

If the publication is distributed under the terms of Article 25fa of the Dutch Copyright Act, indicated by the "Taverne" license above, 


\title{
Validation of the Serbian version of inflammatory Rasch-built overall disability scale in patients with chronic inflammatory demyelinating polyradiculoneuropathy
}

\author{
Stojan Peric $^{1}$ () | Ivo Bozovic ${ }^{1}$ ( ) | Marielle H. J. Pruppers $^{2}$ | Bogdan Bjelica ${ }^{1}$ | \\ Zorica Stevic $^{1}$ | Catharina G. Faber ${ }^{2}$ | Ingemar S. J. Merkies ${ }^{2,3}$ | Ivana Basta ${ }^{1}$
}

${ }^{1}$ Neurology Clinic, Clinical Centre of Serbia, School of Medicine, University of Belgrade, Belgrade, Serbia

${ }^{2}$ Department of Neurology, School of Mental Health and Neuroscience, Maastricht University Medical Center, Maastricht, The Netherlands

${ }^{3}$ Department of Neurology, St. Elisabeth Hospital, Willemstad, Curaçao

\section{Correspondence}

Assoc. Prof. Ivana Basta, MD, PhD,

Department for Neuromuscular Disorders, Neurology Clinic, Clinical Centre of Serbia, School of Medicine, University of Belgrade, 6, Dr Subotic Street, 11000 Belgrade, Serbia. Email: ivanabasta@yahoo.com

Prof. Ingemar Merkies, MD, PhD, School of Mental Health and Neuroscience, Maastricht University Medical Center, Universsiteitsingel 40, 6229 ER Maastricht, The Netherlands. Email: isjmerkies@hotmail.com

Funding information

Ministarstvo Prosvete, Nauke i Tehnološkog Razvoja, Grant/Award Number: \#175083

\begin{abstract}
Inflammatory Rasch-built overall disability scale (I-RODS) seems to be a valid activity measure for use in patients with chronic inflammatory demyelinating polyradiculoneuropathy (CIDP). Our aim was to translate and validate the I-RODS for use in CIDP patients from Serbia. Study comprised 83 patients diagnosed with CIDP. I-RODS was translated and cross-culturally validated using the standard guidelines. Following scales were also administered: Medical Research Council (MRC) sum score, Inflammatory Neuropathy Cause and Treatment (INCAT) sensory and disability scores, Krupp's Fatigue Severity Scale, Beck Depression Inventory, Visual Analogue Scale for pain, and health survey-36 (SF-36) as a quality of life measure. According to the I-RODS, significant proportion of our patients reported that "running" (51\%), "dancing" (41\%), and "standing for hours" (40\%) were impossible tasks to perform, while "teeth brushing" (94\%), "eating" (88\%), and "reading a newspaper/book" (82\%) were noted as the easiest items. Patients with more muscle weakness (lower MRC sum score) and more severe INCAT sensory score had lower I-RODS score $(P<.01)$. Also, patients with fatigue, depression and pain had lower I-RODS scores $(P<.01)$. I-RODS score correlated with the INCAT disability score $(P<0.01)$ was $78 \pm 19$ compared to $51 \pm 30$ in patients with INCAT $>1(P<.01)$. I-RODS score correlated with the total SF-36 score ( $r h o=+0.73, P<.01$ ), as well as with all SF-36 domain scores. Serbian version of the I-RODS seems to be a valid activity measure for use in CIDP patients. I-RODS was able to assess different levels of disability, it was in association with impairment measures, INCAT disability scale and quality of life. Further studies are needed to assess its responsiveness.
\end{abstract}

\section{KEYWORDS}

chronic inflammatory demyelinating polyradiculoneuropathy, disability, impairment, I-RODS, quality of life, validation

\section{1 | INTRODUCTION}

Chronic inflammatory demyelinating polyradiculoneuropathy (CIDP) is an autoimmune, progressive, stepwise, or relapsing-remitting neuropathy, characterized by symmetric proximal and distal weakness, sensory dysfunction, and absent or reduced tendon reflexes of all extremities, which is developing over at least 2 months. ${ }^{1}$ Appropriate outcome measures are needed in order to evaluate efficacy of new therapies in clinical trials for CIDP. Any disease may be evaluated through the three main types of outcome measures: impairment, activity and participation, and 
quality of life (QoL). ${ }^{2}$ Activity and participation scales have been proposed as a primary outcome measure in CIDP clinical trials. ${ }^{3}$

To date, the most used outcome measure for CIDP is the Inflammatory Neuropathy Cause and Treatment (INCAT) disability scale, particularly in its adjusted form. Although widely used, this activity measure is ordinal-based and has limitations which could hamper the comparison between patients and between different trials. ${ }^{4}$ In order to overcome these limitations and ensure exactness, the Inflammatory Rasch-built Overall Disability (I-RODS) scale was created. ${ }^{5-7}$ The Rasch model is a process of creating interval-based measure which could obtain more precise information of disease impact. ${ }^{6,8}$ I-RODS is a patient-reported outcome measure which fulfills the modern scientific requirements and clinimetric criteria. Thus, the ENMC international workshop group recommended that I-RODS should be used as a primary outcome measure in CIDP, because it had demonstrated significantly higher responsiveness compared to the Rasch-transformed ordinal-based INCAT scale. ${ }^{7}$ Also, I-RODS and the INCAT disability scale will be used as activity and participation measures in the international CIDP registry. ${ }^{9}$ Although it seems that I-RODS had a satisfying cross-cultural validation, ${ }^{6}$ this measure has not been used in Eastern European countries so far. PeriNoms study group reported that it would have been ideal to have at least 50 patients per illness and country included in the study to properly evaluate the cross-cultural validation of the I-RODS.

The aim of this study was to translate and validate the I-RODS for use in Serbian patients with CIDP. In addition, we sought to identify the potential factors which influence patients' activities measured by I-RODS, and if activity level measured by I-RODS correlates with patients' QoL.

\section{2 | METHODS AND MATERIALS}

The INeSS (Inflammatory Neuropathy Study of Serbia) was designed in August 2016 with the main goal of collecting as many as patients diagnosed with CIDP from Serbia, Republic of Srpska (Bosnia and Herzegovina) and Montenegro. We sought to comprise all CIDP patients from tertiary health care centers over the last 10-year period between 2007 and 2016. All patients who met the European Federation of Neurological Societies/Peripheral Nerve Society (EFNS/PNS) diagnostic criteria for CIDP were included in the database. ${ }^{1}$ CIDP variants were also diagnosed according to these criteria. ${ }^{1}$ Of the 190 identified patients, 26 have died by the time of testing, 4 were positive for IgM paraproteins (MGUS) and thus excluded, 32 were lost from follow-up, and 28 denied participation in this research. Moreover, nine patients were excluded because of the presence of other severe disorders (hematological malignancy, connective tissue disease, motor neuron disease, stroke, and neurofibromatosis). Eight patients that are diagnosed and treated at the Military Medical Academy in Belgrade did not take part in this research. Finally, the total number of patients tested in 2016 was 83. The Ethical Board of the Neurology Clinic, Clinical Center of Serbia approved this research, and informed consent to participate in this study was obtained from all patients.
Main sociodemographic data (including gender, age, education, profession, and disease duration) were obtained from all patients at time of testing. The presence of significant comorbid disorders such as diabetes mellitus and monoclonal gammopathy of undetermined significance (MGUS) was noted (with the exception of IgM because these patients were excluded). Different therapeutic modalities and response to treatment were also analyzed.

Muscle strength and sensory deficit were considered as impairment measures. In order to examine muscle strength, we used the MRC 0-5 point scale (0-without movement, 5-normal strength). MRC sum score (MRC-SS) evaluates six muscle groups on both sides (shoulder abductors, elbow flexors, wrist extensors, hip flexors, knee extensors, and foot dorsiflexors). ${ }^{10}$ The INCAT sensory score is an impairment measure which we used in order to evaluate objective sensory deficits of our patients. ${ }^{11}$

We also investigated fatigue, depression, and pain. Krupp's Fatigue Severity Scale (FSS) was used in order to estimate severity of fatigue. A score above 36 represented a significant fatigue. ${ }^{12}$ In order to assess level of depression, the Beck Depression Inventory (BDI) was applied. Patients were considered depressed if the score was $\geq 11 .{ }^{13}$ The presence of pain was self-evaluated by all patients, using the Visual Analogue scale (from 0 to 10 points).

To assess patients' activity limitations and participation restrictions we used the INCAT disability scale and I-RODS. ${ }^{14}$ I-RODS is a scale with a list of 24 activities graded in an easy to difficult manner. The easiest question was "Are you able to read a newspaper/book?" and the most difficult one was "Are you able to run?".,15 For each activity mentioned in the questionnaire, patient can respond: not possible to perform (0 point); possible, but with some difficulty (1 point); possible without any difficulty ( 2 points). Overall raw score ranges from 0 to 48 and is subsequently transferred to a convenient centile metric. ${ }^{6}$ Higher score means less limitation in the activity and social participation.

All patients completed the Serbian version of the SF-36 questionnaire as a measure of QoL. ${ }^{16}$ It is a generic measure which comprises eight general health domains: physical functioning (PF), role physical (RP), bodily pain (BP), general health (GH), vitality (VT), social functioning (SF), role emotional (RE), and mental health $(\mathrm{MH})$. Total SF-36 score, physical composite score (PCS), and mental composite score (MCS) are the main scores which summarize these eight domains. All scores range from 0 to 100 , where higher numbers represent better QoL.

\section{3 | TRANSLATION PROCESS AND STATISTICS}

I-RODS was translated and cross-culturally validated using accepted guidelines and standard methodology. ${ }^{17,18}$ The translation process was done by two translators (native Serbian speakers who are bilingual in English) and two inflammatory neuropathy experts (I. B. and S. P.). As a result, the first Serbian version of the I-RODS was created. Two translators (native English speakers who are bilingual in Serbian), translated this version back to English and compared it to the original 
TABLE 1 Main sociodemographic and clinical features of investigated CIDP patients ( $N=83$ )

\begin{tabular}{|c|c|}
\hline \multicolumn{2}{|l|}{ CIDP features } \\
\hline Male gender (n [\%]) & $54(65.1 \%)$ \\
\hline $\begin{array}{l}\text { Age at onset } \\
\quad(\text { years, mean } \pm S D \text { [med]) }\end{array}$ & $54.5 \pm 13.8(54)$ \\
\hline $\begin{array}{l}\text { Age at testing } \\
\quad(\text { years, mean } \pm S D \text { [med]) }\end{array}$ & $62.0 \pm 12.5(63)$ \\
\hline $\begin{array}{l}\text { Disease duration } \\
\quad(\text { years, mean } \pm \mathrm{SD}[\mathrm{med}])\end{array}$ & $7.5 \pm 5.4(7)$ \\
\hline $\begin{array}{l}\text { Education } \\
\quad(\text { years, mean } \pm \mathrm{SD}[\mathrm{med}])\end{array}$ & $12.2 \pm 2.8(12)$ \\
\hline \multicolumn{2}{|l|}{ CIDP variants (\%) } \\
\hline Typical & $68.7 \%$ \\
\hline Pure motor & $8.4 \%$ \\
\hline Focal & $8.4 \%$ \\
\hline Pure sensory & $7.2 \%$ \\
\hline DADS & $4.8 \%$ \\
\hline LSS & $2.4 \%$ \\
\hline \multicolumn{2}{|l|}{ EFN/PNS NCS criteria (\%) } \\
\hline Definite & $81.9 \%$ \\
\hline Probable & $1.2 \%$ \\
\hline Possible & $16.9 \%$ \\
\hline \multicolumn{2}{|l|}{ Comorbid disorders (\%) } \\
\hline Diabetes mellitus & $20.0 \%$ \\
\hline MGUS (IgM or IgA) & $14.5 \%$ \\
\hline \multicolumn{2}{|l|}{$\begin{array}{l}\text { Therapy (any time during } \\
\text { disease course) (\%) }\end{array}$} \\
\hline Oral prednisone & $85.5 \%$ \\
\hline Pulsed i.v. steroids & $16.9 \%$ \\
\hline IVlg & $36.8 \%$ \\
\hline PLEx & $4.8 \%$ \\
\hline \multicolumn{2}{|l|}{$\begin{array}{l}\text { Immunosuppressant } \\
\text { drugs }\end{array}$} \\
\hline Azathioprine & $10.8 \%$ \\
\hline Cyclosporine & $1.2 \%$ \\
\hline Azathioprine + cyclosporine & $1.2 \%$ \\
\hline $\begin{array}{l}\text { MRC-SS } \\
\quad(\text { mean } \pm \text { SD [med] })\end{array}$ & $54.5 \pm 7.3(57)$ \\
\hline \multicolumn{2}{|l|}{$\begin{array}{l}\text { INCAT sensory scale } \\
(\text { mean } \pm \mathrm{SD} \text { [med] })\end{array}$} \\
\hline Arms & $1.4 \pm 2.0$ \\
\hline Legs & $2.8 \pm 2.0$ \\
\hline Total & $4.4 \pm 3.8(3)$ \\
\hline FSS (mean \pm SD) & $34.4 \pm 17.1$ \\
\hline Significant fatigue (\%) & $42.2 \%$ \\
\hline $\mathrm{BDI}($ mean $\pm \mathrm{SD})$ & $8.6 \pm 7.8$ \\
\hline Depressiveness (\%) & $32.5 \%$ \\
\hline VAS (mean \pm SD) & $2.5 \pm 3.0$ \\
\hline Pain (\%) & $56.6 \%$ \\
\hline
\end{tabular}

TABLE 1 (Continued)

\section{CIDP features}

INCAT disability scale (mean \pm SD [med])

$\begin{array}{ll}\text { Arms } & 0.6 \pm 0.8 \\ \text { Legs } & 1.2 \pm 1.4 \\ \text { Total } & 1.8 \pm 2.0(1)\end{array}$

Abbreviations: BDI, Beck Depression Inventory; CIDP, chronic inflammatory demyelinating polyneuropathy; DADS, distal acquired demyelinating symmetric neuropathy; EFNS/PNS, European Federation of Neurological Societies/Peripheral Nerve Society; FSS, Fatigue Severity Scale; INCAT, Inflammatory Neuropathy Cause and Treatment; IVIg, intravenous immunoglobulin; LSS, Lewis-Sumner syndrome; MGUS, monoclonal gammopathy of undetermined significance; MRC-SS, Medical Research Council sum score; NCS, nerve conduction studies; TPE, plasma exchange; VAS, Visual Analogue Scale for pain.

I-RODS. This phase resulted in the second Serbian version which was also evaluated by inflammatory neuropathy experts (I. B. and S. P.). Second version was applied in 10 CIDP patients (native Serbian speakers) and after minor corrections the final Serbian I-RODS version was established.

Normality of data was tested by the Kolmogorov-Smirnov test. MannWhitney $U$ test, Student's $t$ test and $\chi^{2}$ test were used, as appropriate. Because I-RODS is composed of 24 items, internal consistency was also analyzed using Cronbach's alpha (minimal standard was 0.70 for group comparisons and 0.90 for individual comparisons). Percentage of patients obtaining top score (ceiling effect) and bottom score (floor effect) were calculated. Construct-related validity was assessed as an impact of sociodemographic factors on I-RODS: through the Mann-Whitney $U$ test for gender (male vs female), and through the linear regression analysis for age at onset, duration of the disease, age at testing, and education. Criterion-related validity was calculated as an association between I-RODS score and clinical features of the disease using Mann-Whitney $U$ test for CIDP variant (typical vs atypical), nerve conduction study findings (possible vs definite/probable CIDP), diabetes mellitus (present vs absent), and IgG/lgA paraprotein (present vs absent); and by using multiple linear regression analysis weighted for gender and age for INCAT sensory score, MRC-SS, FSS, BDI, and pain. Association between I-RODS score and INCAT disability scale was also analyzed with the multiple linear regression analysis weighted for gender and age representing concurrent validity. In addition, both I-RODS and INCAT disability scale were compared in terms of correlation with SF-36 (Spearman's rho). In all analyses, significant testing was two-sided, with $\alpha$ sets at 0.05 for statistical significance and 0.01 for high statistical significance.

\section{RESULTS}

Male to female ratio of our CIDP patients was 1.9:1 and mean age at testing was $62.0 \pm 12.5$ years (median 63 years). Typical CIDP was diagnosed in $69 \%$ of subjects and $82 \%$ had definite CIDP according to the EFNS/PNS criteria. Other sociodemographic and clinical characteristics of our cohort are presented in Table 1. A total of $32 \%$ of 
patients had symptoms and signs of depressiveness, $42 \%$ complained of significant fatigue, while $57 \%$ reported pain (Table 1 ).

Mean raw I-RODS score was $35.2 \pm 11.7$, while mean centile score was $66.7 \pm 23.5$ (range 6-100, median 67). Cronbach's alpha was 0.96 fulfilling criteria for both group and individual comparison. According to I-RODS, a significant proportion of our patients stated that "running" (51\%), "dancing" (41\%), and "standing for hours" (40\%) were tasks impossible to perform. On the other hand, "teeth brushing" (94\%), "eating" (88\%), and "reading a newspaper/book" (82\%) were noted as the easiest items to perform (Figure 1).

Regarding I-RODS, floor effect (bottom score) was not observed in any of the patients. Ceiling effect (top score) was reported by 16 (19.3\%) patients. Among these, 12 patients had INCAT disability score 0 , two had INCAT 1, and two had INCAT 2 (one in arms + one in legs). When consider INCAT disability scale, floor effect was absent, but ceiling effect was found in even $31 \%$ of CIDP patients.

Sociodemographic features correlated neither with the total I-RODS score nor with the individual I-RODS items (Table 2). On the other hand, INCAT sensory score, MRC-SS, presence of fatigue, depressiveness, and pain, as well as INCAT disability score were in association with the IRODS total score and with number of items on I-RODS $(P<.01)$.

Results on the SF-36 questionnaire and association of both IRODS and INCAT disability scores with SF-36 domains in our CIDP cohort are presented in Table 3. Overall, the I-RODS showed better correlation with all SF-36 scores compared to INCAT (Table 3).

\section{5 | DISCUSSION}

Serbian version of I-RODS is a simple, easily understandable, reliable and valid activity, and social participation scale that can differentiate degrees of disability in CIDP patients. Draak et al underlined that most of CIDP patients showed poor general functionality. ${ }^{19}$ In addition to these findings, our results indicate that CIDP may affect even the simplest daily activities although only some of them were unable to perform the most difficult tasks. I-RODS is able to capture wider range of activities than INCAT disability scale which suggests its sensitivity and relevance for everyday life. Floor effect (bottom score) was not observed in any of the patients which means that I-RODS may make a distinction even between patients with high levels of disability and social participation restriction. On the other hand, ceiling effect (top score) was reported by 16 (19\%) patients which suggest that in the group of patients in remission, I-RODS makes no enough distinction. However, ceiling effect was much higher (31\%) for INCAT disability scale. Furthermore, we believe that I-RODS can capture the slightest relapses of the disease and therefore may be convenient for analyzing patients even during long-term maintenance therapy. ${ }^{20}$ In previous papers, I-RODS ceiling effect was lower (6\% and 9.5\%), but investigated groups were reportedly with higher level of disability compared to ours. ${ }^{8}$ Based on the fact that both INCAT and I-RODS have ceiling effect, it would be of interest to combine this with a scale without ceiling such as six-minute walk test. ${ }^{21}$ However, Draak and colleagues, although not using six-minute walk test itself, showed that improvement of one construct such as walking ability was not able to capture the spectrum of all functional limitations in CIDP. ${ }^{19}$

Mean centile I-RODS score was $66.7 \pm 23.5$ in our cohort with range of 6 to 100. Similar mean score was observed in the PATH study although the range was narrower (51 to 83 ). ${ }^{22}$

I-RODS has been recently suggested as a primary outcome measure for clinical trials in CIDP patients. ${ }^{6,23}$ Further research is needed to demonstrate a responsiveness of the Serbian I-RODS in order to fulfill the criterion of a satisfying outcome measure for clinical trials. ${ }^{7}$ I-RODS
FIGURE 1 Distribution of patients' responses on each item of the I-RODS ( $\mathrm{N}=83)$. Results are presented as a percentage of patients giving certain response. * Missing answer in one (1\%) patient

$$
\begin{aligned}
& \text { - Not possible to perform } \\
& \square \text { Possible, without any dfficulty } \quad \square \text { Missing answer }
\end{aligned}
$$

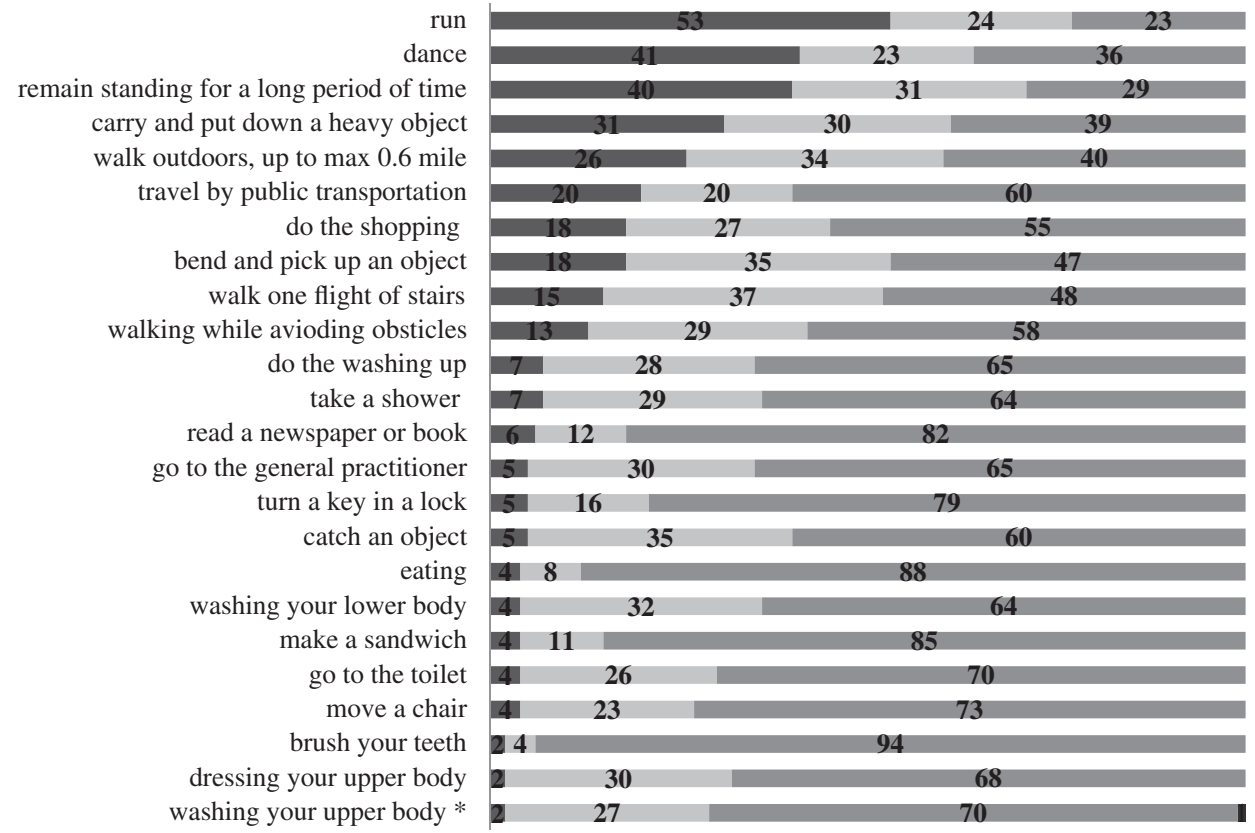


TAB LE 2 Construct-, criterion-, and concurrent-related validity of the I-RODS ( $N=83)$

\begin{tabular}{|c|c|c|}
\hline Investigated feature & Association with I-RODS score & $\begin{array}{l}\text { Association with individual I-RODS items at the level } \\
\text { of } P<.01\end{array}$ \\
\hline $\begin{array}{l}\text { Gender } \\
\text { Male } \\
\text { Female }\end{array}$ & None & None \\
\hline Age at onset & None & None \\
\hline Age at testing & None & None \\
\hline Education & None & None \\
\hline $\begin{array}{l}\text { CIDP variant } \\
\text { Typical } \\
\text { Atypical }\end{array}$ & None & None \\
\hline $\begin{array}{l}\text { Diabetes mellitus } \\
\text { Present } \\
\text { Absent }\end{array}$ & None & None \\
\hline $\begin{array}{l}\text { IgG/IgA paraprotein } \\
\text { Present } \\
\text { Absent }\end{array}$ & None & None \\
\hline MRC-SS & Beta $=0.66 *$ adjusted $R^{2}=0.45$ & $\begin{array}{l}\text { Wash your upper body; go to the toilet; dress your upper body; } \\
\text { wash your lower body; turn a key in a lock; go to the general } \\
\text { practitioner; take a shower; do the washing up; do the } \\
\text { shopping; catch an object; bend and pick up an object; walk } \\
\text { one flight of stairs; travel by public transportation, walk while } \\
\text { avoiding obstacles; walk outdoor s, up to max } 0.6 \text { mile; carry } \\
\text { and put down a heavy object; dance; remain standing for a } \\
\text { long period of time; run }\end{array}$ \\
\hline Fatigue & Beta $=-0.71 *$ adjusted $R^{2}=0.48$ & $\begin{array}{l}\text { Wash your upper body; go to the toilet; dress your upper body; } \\
\text { wash your lower body; move a chair; go to the general } \\
\text { practitioner; take a shower; do the washing up; do the } \\
\text { shopping; catch an object; bend and pick up an object; walk } \\
\text { one flight of stairs; travel by public transportation, walk while } \\
\text { avoiding obstacles; walk outdoor s, up to max } 0.6 \text { mile; carry } \\
\text { and put down a heavy object; dance; remain standing for a } \\
\text { long period of time, run }\end{array}$ \\
\hline Depressiveness & Beta $=-0.44 *$ adjusted $R^{2}=0.18$ & $\begin{array}{l}\text { Dress your upper body; wash your upper body; go to the } \\
\text { general practitioner; do the washing up; do the shopping; } \\
\text { catch an object; bend and pick up an object; walk one flight } \\
\text { of stairs; travel by public transportation, walk while avoiding } \\
\text { obstacles; walk outdoor s, up to max } 0.6 \text { mile; carry and put } \\
\text { down a heavy object; dance; remain standing for a long } \\
\text { period of time; run }\end{array}$ \\
\hline Pain & Beta $=-0.31 *$ adjusted $\mathrm{R}^{2}=0.09$ & $\begin{array}{l}\text { Move a chair; go to the general practitioner; do the shopping; } \\
\text { catch an object; bend and pick up an object; walk one flight } \\
\text { of stairs; travel by public transportation, walk while avoiding } \\
\text { obstacles; walk outdoor s, up to max } 0.6 \text { mile; carry and put } \\
\text { down a heavy object; dance; remain standing for a long } \\
\text { period of time; run }\end{array}$ \\
\hline
\end{tabular}


TABLE 2 (Continued)

\begin{tabular}{|c|c|c|}
\hline Investigated feature & Association with I-RODS score & $\begin{array}{l}\text { Association with individual I-RODS items at the level } \\
\text { of } P<.01\end{array}$ \\
\hline INCAT disability score & Beta $=-0.71 *$ adjusted $\mathrm{R}^{2}=0.51$ & $\begin{array}{l}\text { Wash your upper body; go to the toilet; make a sandwich; dress } \\
\text { your upper body; wash your upper body; move a chair; turn a } \\
\text { key in a lock; go to the general practitioner; take a shower; do } \\
\text { the washing up; do the shopping; catch an object; bend and } \\
\text { pick up an object; walk one flight of stairs; travel by public } \\
\text { transportation, walk while avoiding obstacles; walk outdoor s, } \\
\text { up to max } 0.6 \text { mile; carry and put down a heavy object; } \\
\text { dance; remain standing for a long period of time; run }\end{array}$ \\
\hline
\end{tabular}

Note: Association of sociodemographic variables with I-RODS score was made by using Mann-Whitney $U$ test for nominal variables and linear regression analysis for ordinal and continuous variables. Association of clinical variables with I-RODS score was made by using multiple linear regression analysis weighted for gender and age.

Abbreviations: CIDP, chronic inflammatory demyelinating polyneuropathy; INCAT, Inflammatory Neuropathy Cause and Treatment; I-RODS, inflammatory Rasch-built overall disability scale; MRC-SS, Medical Research Council sum score; NCS, nerve conduction studies.

$* P<.01$.

TAB LE 3 Correlation of I-RODS and INCAT disability scale with SF-36 scores in CIDP patients $(\mathrm{N}=83)$

\begin{tabular}{|c|c|c|c|}
\hline SF-36 score & Mean \pm SD & $\begin{array}{l}\text { Correlation } \\
\text { with } \\
\text { I-RODS } \\
\text { score (rho) }\end{array}$ & $\begin{array}{l}\text { Correlation } \\
\text { with INCAT } \\
\text { disability } \\
\text { scale (rho) }\end{array}$ \\
\hline $\begin{array}{l}\text { Physical } \\
\text { functioning (PF) }\end{array}$ & $49.7 \pm 34.0$ & $0.77 *$ & $-0.64 *$ \\
\hline Role physical (RF) & $42.3 \pm 42.9$ & $0.69 *$ & $-0.52 *$ \\
\hline Bodily pain (BP) & $60.9 \pm 30.0$ & $0.50 *$ & $-0.39 *$ \\
\hline $\begin{array}{l}\text { General health } \\
\text { (GH) }\end{array}$ & $54.1 \pm 23.3$ & $0.55^{*}$ & $-0.46 *$ \\
\hline Vitality (VT) & $55.8 \pm 25.5$ & $0.51 *$ & $-0.42 *$ \\
\hline $\begin{array}{l}\text { Social } \\
\text { functioning (SF) }\end{array}$ & $71.0 \pm 26.8$ & $0.48 *$ & $-0.39 *$ \\
\hline Role emotional (RE) & $53.1 \pm 46.5$ & $0.52 *$ & $-0.48 *$ \\
\hline Mental health (MH) & $63.6 \pm 20.3$ & $0.44 *$ & $-0.40 *$ \\
\hline $\begin{array}{l}\text { Physical composite } \\
\text { score (PCS) }\end{array}$ & $52.6 \pm 26.1$ & $0.76 *$ & $-0.61 *$ \\
\hline $\begin{array}{l}\text { Mental composite } \\
\text { score (MCS) }\end{array}$ & $59.5 \pm 23.7$ & $0.62 *$ & $-0.54 *$ \\
\hline Total SF-36 score & $56.3 \pm 24.9$ & $0.73 *$ & $-0.61 *$ \\
\hline
\end{tabular}

responsiveness has been previously showed, ${ }^{6,24}$ and the questionnaire have been used in clinical trials already. ${ }^{20}$ High Cronbach's alpha of the Serbian version suggest that questionnaire may be able to compare not only a whole group of patients, but also between individual patients.

No significant associations were observed between I-RODS and sociodemographic factors of CIDP patients. Thus, I-RODS is a measure that may be applied in all CIDP patients, independent of gender, age, disease duration, education, CIDP variant, nerve conduction study findings, presence of diabetes, or IgG/IgA paraprotein. On the other hand, I-RODS well differentiated between different grades of impairment in CIDP measured by MRC-SS and INCAT sensory scale which once again confirms its relevance. Similarly, correlation between I-RODS and hand grip strength as an objective impairment measure has been previously reported. ${ }^{15}$
Our findings suggest that patients' abilities are significantly affected by presence of depressiveness, fatigue, and pain. These associations have not been commonly investigated so far in CIDP patients. However, it is well known that depression and fatigue are significant predictors of worse QoL in CIDP. ${ }^{25,26} \mathrm{~A}$ recent study on anti-myelin-associated glycoprotein neuropathy patients showed that I-RODS correlated with the total pain score. ${ }^{27}$ Thus, patients with CIDP should be properly screened for the presence of depression, fatigue, and pain because these potentially treatable disorders may affect patients' abilities, social participations, and QoL.

In our research, worse INCAT disability scores were in association with worse I-RODS score. However, it should be noticed that I-RODS is a more sensitive outcome measure. ${ }^{7}$ Moreover, ordinaloriented measures such as INCAT have significant limitations, such as the fact that individual items of the sum scores are not equalweighted and cannot be presented linearly. Thus, slight but important clinically changes could be easily overlooked by ordinal-based measures. $^{5}$ On the other hand, I-RODS is more suitable for detecting differences, while a change of one point on INCAT disability scale can be implied on narrow range of clinical presentations. ${ }^{5}$ I-RODS represents the patient's selection of many everyday activities reflecting general functionality.

Both INCAT disability scale and I-RODS correlated with the SF-36 score and its individual domains. Similar correlations of INCAT and SF-36 score have been previously reported. ${ }^{25,27,28}$ Correlation measured by Spearman's rho was stronger for I-RODS than for INCAT. Similarly, the association between the I-RODS and EuroQoL thermometer was consistently higher compared with the association between INCAT ONLS and EuroQoL thermometer. ${ }^{24}$ This can be explained due to the better statistical properties of I-RODS (ordinalbased vs interval-based scale) and due to the wider range of relevant abilities captured by I-RODS. Although ability measures (both INCAT and I-RODS) were found to correlate with all SF-36 domains, association was expectedly stronger for the physical domains, that is, PF and RP. Also, correlation with PCS was stronger than with MCS. 


\section{6 | CONCLUSION}

Serbian version of the I-RODS is a simple, easily understandable, reliable and valid activity, and social participation scale that can be applied in different subgroups of CIDP patients and can differentiate degrees of their disability. I-RODS seems to be more sensitive than INCAT and showed stronger correlation with QoL than INCAT. Further research is needed to demonstrate responsiveness of the Serbian I-RODS.

\section{7 | LIMITATIONS}

The limitation of the study is the fact that the original FSS was used to evaluate the presence of fatigue instead of the modified Raschbuilt fatigue severity scale. ${ }^{29}$ Another important limitation of this study is the shortage of follow-up data so we were not able to calculate responsiveness. However, this would be our future goal.

\section{ACKNOWLEDGEMENTS}

This study was supported by the Ministry of Education, Science and Technological Development of the Republic of Serbia (\#175083).

\section{CONFLICT OF INTEREST}

All authors declare no conflicts of interest, and have contributed to the study design and manuscript revision.

\section{ORCID}

Stojan Peric (D) https://orcid.org/0000-0002-2979-556X Ivo Bozovic (D) https://orcid.org/0000-0002-6623-0779

\section{REFERENCES}

1. Van den Bergh PYK, Hadden RDM, Bouche $P$, et al. European Federation of Neurological Societies/Peripheral Nerve Society Guideline on management of chronic inflammatory demyelinating polyradiculoneuropathy: report of a joint task force of the European Federation of Neurological Societies and the Peripher. Eur J Neurol. 2010; 17(3):356-363.

2. U.S. Department of Health and Human Services FDA Center for Drug Evaluation and Research, U.S. Department of Health and Human Services FDA Center for Biologics Evaluation and Research, U.S. Department of Health and Human Services FDA Center for Devices and Radiological Health. Guidance for industry: patientreported outcome measures: use in medical product development to support labeling claims: draft guidance. Health Qual Life Outcomes. 2006;4:79.

3. Merkies IS, Lauria G. 131st ENMC international workshop: selection of outcome measures for peripheral neuropathy clinical trials 10-12 December 2004, Naarden, The Netherlands. Neuromuscul Disord. 2006;16(2):149-156.

4. Merkies IS, Lauria G, Faber CG. Outcome measures in peripheral neuropathies: requirements through statements. Curr Opin Neurol. 2012; 25(5):556-563
5. Allen JA, Gelinas DF, Lewis RA, et al. Optimizing the use of outcome measures in chronic inflammatory demyelinating polyneuropathy. US Neurol. 2017;13(1):26-34.

6. Draak TH, Vanhoutte EK, van Nes SI, et al. Changing outcome in inflammatory neuropathies: Rasch-comparative responsiveness. Neurology. 2014;83:2124-2132.

7. Vanhoutte EK, Faber CG, Merkies IS. 196th ENMC international workshop: outcome measures in inflammatory peripheral neuropathies 8-10 February 2013, Naarden, The Netherlands. Neuromuscul Disord. 2013;23:24-933.

8. van Nes SI, Vanhoutte EK, van Doorn PA, et al. Rasch-built Overall Disability Scale (R-ODS) for immune-mediated peripheral neuropathies. Neurology. 2011;25;76(4):337-345.

9. Eftimov F, Bunschoten C, Rajabally Y, et al. 231st ENMC International Workshop: International Standard for CIDP Registry and Biobank, Naarden, The Netherlands, 12-14 May 2017. Neuromuscul Disord. 2018;28(2):178-184.

10. Kleyweg RP, van der Meché FG, Schmitz PI. Interobserver agreement in the assessment of muscle strength and functional abilities in Guillain-Barré syndrome. Muscle Nerve. 1991;14(11): 1103-1109.

11. Draak THP, Vanhoutte EK, van Nes SI, et al. Comparing the NIS vs. MRC and INCAT sensory scale through Rasch analyses. J Peripher Nerv Syst. 2015;20(3):277-288.

12. Krupp LB, LaRocca NG, Muir-Nash J, Steinberg AD. The fatigue severity scale. Application to patients with multiple sclerosis and systemic lupus erythematosus. Arch Neurol. 1989;46(10): 1121-1123.

13. Beck AT, Steer RA, Carbin MG. Psychometric properties of the Beck Depression Inventory: twenty-five years of evaluation. Clin Psychol Rev. 1988;8(1):77-100.

14. Breiner A, Barnett C, Bril V. INCAT disability score: a critical analysis of its measurement properties. Muscle Nerve. 2014;50(2):164-169.

15. Draak TH, Gorson KC, Vanhoutte EK, et al. Correlation of the patient's reported outcome inflammatory-RODS with an objective metric in immune-mediated neuropathies. Eur J Neurol. 2016;23(7): 1248-1253.

16. http://www.qualitymetric.com. SF-36 Health Survey (Original version) Language Recalls.

17. Acquadro C, Conway K, Giroudet C, et al. Linguistic Validation Manual for Patient-Reported Outcomes (PRO) Instruments. Lyon, France: Mapi Research Institute; 2004.

18. Assessing health status and quality-of-life instruments: attributes and review criteria. Qual Life Res. 2002;11(3):193-205.

19. Draak TH, Gorson KC, Vanhoutte EK, et al. Does ability to walk reflect general functionality in inflammatory neuropathies? J Peripher Nerv Syst. 2016;21(2):74-81.

20. Katzberg HD, Latov N, Walker FO. Measuring disease activity and clinical response during maintenance therapy in CIDP: from ICE trial outcome measures to future clinical biomarkers. Neurodegener Dis Manag. 2017;7(2):147-156.

21. Spina $E$, Topa A, lodice $R$, et al. Six-minute walk test is reliable and sensitive in detecting response to therapy in CIDP. J Neurol. 2019; 266(4):860-865.

22. van Schaik IN, Bril V, van Geloven N, et al. Subcutaneous immunoglobulin for maintenance treatment in chronic inflammatory demyelinating polyneuropathy (PATH): a randomised, doubleblind, placebo-controlled, phase 3 trial. Lancet Neurol. 2018;17(1): 35-46.

23. Vanhoutte EK, Draak TH, Gorson KC, et al. Impairment measures versus inflammatory RODS in GBS and CIDP: a responsiveness comparison. J Peripher Nerv Syst. 2015;20(3):289-295.

24. Merkies IS, Kieseier BC. Fatigue, pain, anxiety and depression in Guillain-Barré syndrome and chronic inflammatory demyelinating polyradiculoneuropathy. Eur Neurol. 2016;75(3-4):199-206. 
25. Bozovic I, Kacar A, Peric S, et al. Quality of life predictors in patients with chronic inflammatory demyelinating polyradiculoneuropathy. J Neurol. 2017;264(12):2481-2486.

26. Rajabally YA, Delmont E, Hiew FL, et al. Prevalence, correlates and impact of pain and cramps in anti-MAG neuropathy: a multicentre European study. Eur J Neurol. 2018;25(1):135-141.

27. Merkies ISJ, Schmitz PIM. Getting closer to patients: the INCAT overall disability sum score relates better to patients' own clinical judgement in immune-mediated polyneuropathies. J Neurol Neurosurg Psychiatry. 2006;77:970-972.

28. Kacar A, Bjelica B, Bozovic I, et al. Neuromuscular disease-specific questionnaire to assess quality of life in patients with chronic inflammatory demyelinating polyradiculoneuropathy. J Peripher Nerv Syst. 2018;23(1):11-16.
29. van Nes SI, Vanhoutte EK, Faber CG, et al. Improving fatigue assessment in immune-mediated neuropathies: the modified Rasch-built fatigue severity scale. J Peripher Nerv Syst. 2009;14(4):268-278.

How to cite this article: Peric S, Bozovic I, Pruppers MHJ, et al. Validation of the Serbian version of inflammatory Rasch-built overall disability scale in patients with chronic inflammatory demyelinating polyradiculoneuropathy. J Peripher Nerv Syst. 2019;24:260-267. https://doi.org/10.1111/jns.12343 